\title{
Tuition Fees and Sunk-cost Effects
}

Citation for published version (APA):

Ketel, N., Linde, J., Oosterbeek, H., \& van der Klaauw, B. (2016). Tuition Fees and Sunk-cost Effects. The Economic Journal, 126(598), 2342-2362. https://doi.org/10.1111/ecoj.12297

Document status and date:

Published: 01/12/2016

DOI:

10.1111/ecoj.12297

Document Version:

Accepted author manuscript (Peer reviewed / editorial board version)

\section{Please check the document version of this publication:}

- A submitted manuscript is the version of the article upon submission and before peer-review. There can be important differences between the submitted version and the official published version of record.

People interested in the research are advised to contact the author for the final version of the publication, or visit the DOI to the publisher's website.

- The final author version and the galley proof are versions of the publication after peer review.

- The final published version features the final layout of the paper including the volume, issue and page numbers.

Link to publication

\footnotetext{
General rights rights.

- You may freely distribute the URL identifying the publication in the public portal. please follow below link for the End User Agreement:

www.umlib.nl/taverne-license

Take down policy

If you believe that this document breaches copyright please contact us at:

repository@maastrichtuniversity.nl

providing details and we will investigate your claim.
}

Copyright and moral rights for the publications made accessible in the public portal are retained by the authors and/or other copyright owners and it is a condition of accessing publications that users recognise and abide by the legal requirements associated with these

- Users may download and print one copy of any publication from the public portal for the purpose of private study or research.

- You may not further distribute the material or use it for any profit-making activity or commercial gain

If the publication is distributed under the terms of Article $25 \mathrm{fa}$ of the Dutch Copyright Act, indicated by the "Taverne" license above, 


\title{
Tuition fees and sunk-cost effects*
}

\author{
Nadine Ketel ${ }^{\dagger} \quad$ Jona Linde ${ }^{\ddagger}$ \\ Hessel Oosterbeek $^{\S} \quad$ Bas van der Klaauw $^{\text {It }}$
}

\begin{abstract}
This paper reports on a field experiment testing for sunk-cost effects in an education setting. Students signing up for extra-curricular tutorial sessions randomly received a discount on the tuition fee. The sunk-cost effect predicts that students who pay more will attend more tutorial sessions, with possibly beneficial effects on their performance. For our full sample, we find no support for this hypothesis, neither on attendance nor on performance. Results are consistent with a sunk-cost effect for the subsample of students who, based on hypothetical survey questions, are identified as sunk-cost prone. We do not find differential effects by students' income or parental contributions.
\end{abstract}

JEL-codes: C93; D03; I22

Key-words: Sunk-cost effect; Higher education; Field experiment

\section{Introduction}

Education is heavily subsidized around the world. These subsidies can lower student effort and performance through two channels. First, higher subsidies attract more students and the additional students may be weaker or less motivated than the average student. ${ }^{1}$ Second,

\footnotetext{
*This version: March 2015. We gratefully acknowledge valuable comments from two anonymous referees, from Kjell Salvanes (the editor) and from seminar participants at various places. We thank de Bijlespartner and the instructors of the tutorials for their cooperation. We appreciate financial support from the University of Amsterdam through the Speerpunt Behavioral Economics.

$\dagger$ VU University Amsterdam; University of Amsterdam; Tinbergen Institute

*VU University Amsterdam; Tinbergen Institute

$\S$ University of Amsterdam; TIER

IVU University Amsterdam; Tinbergen Institute; CEPR; IZA

${ }^{1}$ Studies showing that lower tuition fees or more financial aid increase enrollment include Van der Klaauw (2002), Kane (2003) and Dynarski (2003).
} 
higher subsidies may - net of selection - reduce student effort through a sunk-cost effect (Thaler, 1980; Arkes and Blumer, 1985). Students who pay less for their study may have lower psychological costs of failing their studies than students who pay the full price. In this paper we present the results of a field experiment which examines this second channel. ${ }^{2}$

We run a field experiment in which we randomly subsidize Dutch university students who have signed up for a course of extra-curricular tutorial sessions. When participants come to pay the offer price, they may randomly receive an unexpected discount. As a result treated and control participants have, on average, the same willingness to pay, but the actual transaction prices they paid differ. The size of the discount is determined by randomly picking a closed envelope, so participants have no reason to believe that the discount is related to the quality of the course.

Sunk-cost effects can operate through loss aversion, through a taste for consistency or through psychological commitment (Ashraf et al., 2010). ${ }^{3}$ Thaler (1980) discusses not ignoring sunk costs as one of various deviations from the rational maximizing model that follow from Kahneman and Tversky's prospect theory. Eyster (2002) presents a model in which people have a taste for rationalizing past actions by taking current actions for which those past actions were optimal. Having spend a larger amount of money on an extra-tutorial course in the past may then lead to a higher probability of attending a session today.

If the sunk-cost effect would be the only bias to which students are subject, it could make them spend more than the optimal amount of effort on their education. ${ }^{4}$ There is, however, ample evidence that due to present bias - the tendency to place too much weight on the present compared to the future relative to the comparison of two future dates (see e.g. Frederick et al. (2002)) -, students generally spend too little effort on their studies (Koch et al., 2014). ${ }^{5}$ Education requires a large investment upfront, in tuition, time and effort. A present-biased student may be unwilling to make such investments, even if the rewards justify the costs from the perspective of the student herself when both costs and rewards are still in

\footnotetext{
${ }^{2}$ A third channel, potentially operating in the opposite direction, is an income effect. Students who pay the full price have reduced wealth, and may, therefore, work more and "consume" fewer tutorial sessions. We assess the importance of income effects for our study in Section 4.

${ }^{3}$ While tuition fees may trigger some psychological commitment, such pay-in-advance purchases should not be labeled "commitment devices" according to Bryan et al. (2010), because they do not make certain - currently undesirable - future choices more expensive.

${ }^{4}$ Although this should be considered relative to the money and effort sunk on other activities which compete for their time. E.g. if students have sunk a large amount of money and/or effort into their membership of a fraternity or sports team money spend on college tuition may offset these sunk-cost effects.

${ }^{5}$ For example, Levitt et al. (2012) find that rewards to perform well on a test only have an impact when students know that payment is immediate, and not when they know that payment is delayed. This holds for financial rewards as well as for non-financial rewards.
} 
the future. However, due to the sunk-cost effect an initial investment in terms of (high) tuition fees can offset the present bias. ${ }^{6}$ This would be particularly effective if, as seems plausible, it is mainly the daily study effort which is affected by the present bias rather than the more carefully considered financial investment in tuition fees.

There is surprisingly little solid empirical evidence about the sunk-cost bias. For a long time, only Arkes and Blumer (1985) provided evidence. They demonstrate the sunk-cost effect by randomly providing theater patrons with a discount. Participants who received a discount visited the theater significantly less often. This is, however, only the case for the first half of the theater season; in the second half differences between the discount and the no-discount group are no longer significant. ${ }^{7}$

Three recent studies investigate the sunk-cost effect in field experiments in developing countries. Ashraf et al. (2010) conducted an experiment in a door-to-door sale of a water purification product to about one thousand households in Zambia. To disentangle selection effects from the sunk-cost effect, they use a clever two-stage pricing design that created random and orthogonal variation in offer prices and transaction prices. Two weeks after the sale, data were collected concerning usage of the product. The study finds no evidence of a sunk-cost effect: households that pay a higher transaction price are not more likely to use the product. If, however, paying a positive price is compared to paying nothing, the point estimates are consistent with the sunk-cost effect, but are not significantly different from zero.

Cohen and Dupas (2010) use a similar two-stage design to estimate the impact of the offer and transaction prices on the use of antimalarial insecticide-treated bed nets offered by prenatal clinics to pregnant women in Kenya. They also fail to find a significant sunk-cost effect. The point estimates are negative, even when paying something is compared to paying nothing.

Finally, Hidalgo et al. (2013) report about an experiment where free school uniforms were provided to primary school children in deprived areas in Ecuador. To minimize selection effects, the provision of free uniforms to treatment schools was not publicly announced and the analysis focuses on students in the last two years of primary school. This study finds

\footnotetext{
${ }^{6}$ Education subsidies may also help to overcome present bias as they lower the required investment. Larger financial aid to students combined with higher tuition fees may be a way out of this dilemma.

${ }^{7}$ The sunk-cost bias has also been investigated in laboratory experiments. Phillips et al. (1991) report that some participants exhibit the sunk-cost effect when they value lottery tickets, while others experience the reverse effect. Friedman et al. (2007) find a small sunk-cost bias in a search task, but the results are very sensitive to the details of the task. Offerman and Potters (2006) show that higher entry fees facilitate cooperation and Meyer (1993) that higher entree fees increase bids in an auction.
} 
a significantly negative effect of free provision of uniforms on school attendance measured during three unannounced visits, which is consistent with the sunk-cost effect.

There are important differences between the studies of Ashraf et al. (2010) and Cohen and Dupas (2010), and those of Hidalgo et al. (2013) and ourselves. The first difference is that the discounts offered are far smaller in the first two studies, also compared to the participants' earnings. A larger discount should increase the chance of finding a sunk-cost effect, which could explain why Ashraf et al. (2010) and Cohen and Dupas (2010) do not find a sunk-cost effect and Hidalgo et al. (2013) do (cf. Garland and Newport, 1991; Rodrik, 2009). However, as a percentage of the total costs of education the discount is small in Hidalgo et al. (2013) and our paper, especially if opportunity costs such as forgone income are included. The second difference is the type of product, health versus education. It may be that when health is concerned people are less likely to make explicit cost-benefit comparisons, but it is not clear what that means for the sunk-cost bias. On the one hand explicit comparisons may lead to more rational decisions and therefore reduce the bias, on the other hand explicit comparisons make the cost more salient which could increase the bias.

The health and education products that we compare here, also differ in the opportunity costs involved in using them. While water purification bottles and bed nets may have alternative usages, these are quite limited for education. In contrast attending school or university involves the use of time which may have a high opportunity cost. This is also the case in Thaler's (1980) classic examples of driving 60 miles in a snowstorm to a basketball game, and continuing playing tennis with an injury.

It is not a priori clear whether the context of our experiment makes it more or less likely to find evidence for sunk-cost effects than in the other studies. The participants in our study are drawn from a population of university students and, therefore, they are probably more rational than the participants in the studies of Ashraf et al. (2010), Cohen and Dupas (2010) and Hidalgo et al. (2013) who come from poor families in developing countries. At the same time, the participants in these studies probably all had previous experiences with buying and using water purification bottles, mosquito bed nets and school uniforms. This is likely to improve the quality of the decision under study. In contrast, a majority of the students in our sample have no previous experience with extra-curricular courses.

The main result of this paper is that we do not find a significant effect of sunk costs on attendance or performance when we study the full sample. To inquire whether the absence of sunk-cost effects is due to income effects, we have estimated whether there are differential effects for students with above and below median monthly income, and for students who paid themselves for the course or whose parents paid. Differences between these groups turn 
out to be minor, indicating that income effects do not explain our main result. Following Ashraf et al. (2010) we have also looked at the subsample of students who on the basis of hypothetical survey questions can be categorized as sunk-cost prone. For this subsample we find a significant sunk-cost effect on attendance: sunk-cost prone students who receive a larger discount are less likely to attend. We acknowledge, however, that the measurement of sunk-cost proneness has some caveats.

The remainder of this paper is structured as follows, Section 2 describes the setting of our study, the experimental design and the data. Section 3 briefly discusses our empirical approach. Section 4 presents and discusses the results. Section 5 summarizes and concludes.

\section{Design and data}

\subsection{Setting}

Our field experiment concerns students participating in extra-curricular tutorial sessions for various courses at four Dutch universities. These sessions are offered by De Bijlespartner, a company organizing additional tutorial sessions for students in cooperation with several local study associations. This company provides study materials and recruits more senior students, who performed well on the subject, as teachers. Each tutorial group contains between eight and 13 students. Tutorial sessions are connected to a course offered in the regular curriculum and these sessions run concurrently with that course. Courses at Dutch universities typically last seven or eight weeks, the tutorial sessions take place during the final four or five weeks. ${ }^{8}$ Each week there is one tutorial session of two or three hours. Students register online through their study association's website for the tutorial sessions. At the start of the first session, participants pay for the full set of four or five sessions. The listed price for a set of tutorial sessions varies somewhat between courses and is either $€ 60, € 65$ or $€ 75$. The prices are not affected by our experiment; the company offers similar tutorials for the same prices in other periods during the academic year.

The experiment involved five study programs at four Dutch universities: business administration and psychology at the VU University Amsterdam, economics and business at the University of Amsterdam, social sciences at Utrecht University, and psychology at the University of Groningen. For each study program we carried out the experiment only during one block of courses to prevent that students would expect to get a discount. In total, we included

\footnotetext{
${ }^{8}$ The tutorial sessions start later than the course so that students can decide in the first weeks whether or not to take the additional tutorial sessions.
} 
tutorial sessions for 14 courses in our experiment. All courses are offered under the name of the student association of the study program (not under the name of the company) which ensures that students would not expect a discount when hearing about discounts in other study programs. The courses for which the tutorial sessions are offered are mainly statistics or math courses because students find these courses particularly difficult. Table A1 in online Appendix A lists for each study program the courses for which tutorial sessions were offered, the full price, and the numbers of groups and participating students.

\subsection{Experimental design}

The goal of our field experiment is to study whether education subsidies affect study effort and performance net of their impact through the enrollment decision. In particular, we test for the presence of a sunk-cost effect. To generate variation in tuition fees independent of students' willingness to pay, we randomly gave an unexpected discount to students who already signed up and were ready to pay the full tuition fee. We introduced four possible discounts: a full discount (treatment Free), a discount of the full price minus $€ 10$ (treatment Large Discount; LD), a discount of $€ 10$ (treatment Small Discount; SD) and no discount (treatment Full Price). All students have an equal ex ante probability to receive each discount level.

For the experiment we took control of the payment process for the tutorial sessions. When students registered for a set of tutorial sessions, they were informed that they had to pay in cash at the start of the first session. When students arrived we invited them to participate in a study on study behavior and informed them that they could get a discount. Students were not informed about the goal of our study and were not told why randomly different discounts were offered. $^{9}$ Upon agreeing to participate students completed a questionnaire in which they also gave permission to use their information for this study. ${ }^{10}$ The questionnaire asked, among other things, about study habits, maximum willingness to pay and how much they thought the tutorial would help them to pass the relevant exam. An English translation of this pre-treatment questionnaire is in online Appendix C.

After completing the questionnaire students entered a classroom one at a time to determine their discount and pay the remaining tuition fee. They were told that they had an

\footnotetext{
${ }^{9}$ Giving random discounts is comparable to the procedure marketing firms frequently use when they reward respondents to a questionnaire by giving them the chance to win a valuable item instead of paying all respondents a small amount. It is therefore unlikely that participants will infer that they are part of a randomized experiment.

${ }^{10}$ Only two out of 373 students refused to participate and they paid the full price. Students who did not show up for the first session or registered for the tutorial session after the official deadline were not allowed to participate in our experiment.
} 
equal chance to receive any of the four possible discounts, and that the discount would be determined by choosing a closed envelope. Before arrival of the students we prepared the envelopes with discount tickets, including an equal number of envelopes for each discount. When a student picked an envelope, this envelope was not replaced. The number of envelopes was such that the final student could choose from at least four envelopes. We chose this procedure to make it very clear to participants that the discount is randomly determined and unrelated to the quality of the tutorial sessions. This avoids that students infer something about the quality of the course from the transaction price they paid. We asked students not to reveal their discount when leaving the room to prevent students who had not paid yet from updating probabilities for specific discounts.

During the course the teachers recorded students' attendance at each session and reported this to us after the course. During the final tutorial session students filled out the usual evaluation form to which we added some questions. These questions included a control question to check whether students remembered their discount, their opinion about the discount and hypothetical sunk-cost questions. An English translation of the post-treatment questionnaire can be found in online Appendix C. If students were not present at the final session we contacted them to complete the evaluation form either through email or over the phone. ${ }^{11}$ The response rate is $94 \%$. The results in table B1 in the online appendix show that response is slightly higher in the group that received the large discount than in the group that received the full price treatment, and that students in the free treatment are more likely than students in the full price treatment to have responded through email. Since the share that responds through email is rather small (0.04), this difference involves only few students. ${ }^{12}$ Finally, from the university administrations we received grades for the exams of the regular course connected to the tutorial sessions.

A possible contaminator to the sunk-cost effect is an income effect operating in the opposite direction. We asked students whether they paid for the tutorial sessions themselves or whether they received extra money from others, for example, their parents. We also asked students about their monthly income. The income effect may be less important for students whose parents pay for the course and for students with a relatively high income. We discuss findings for these groups in subsection 4.2.

Following Ashraf et al. (2010) we included hypothetical sunk-cost questions in the post-

\footnotetext{
${ }^{11}$ In total 70 students were not present during the last session. Of these students 14 answered the questionnaire by mail, 38 over the phone and 18 did not answer the questionnaire at all.

${ }^{12}$ Eight students in the free treatment answered through email. In the other groups these numbers are zero (large discount), three (small discount) and three (full price).
} 
treatment survey, which allows us to identify sunk-cost-prone people. We asked participants "suppose you bought a bottle of juice for $€ 2$. When you start to drink it, you realize you don't really like the taste. Would you finish drinking it?" Next, we asked two follow-up questions, for $€ 5$ and $€ 1$, "Now suppose you bought exactly the same bottle of juice for $€$.. . Would you finish drinking it?". A participant is categorized as sunk-cost prone if s/he always finishes the bottle, or finishes the bottle when a high price has been paid and doesn't finish the bottle when a lower price has been paid.

One could argue that asking participants the hypothetical sunk-cost questions in the posttreatment questionnaire may lead to respondents to try to rationalize their behavior. However, the question was about juice, so students had to make the link from buying juice to paying for tutorial sessions. Next, it requires that students know how often they would have attended class when given another discount. Moreover, asking these questions in the pre-treatment survey is less attractive because it might make the purpose of the experiment explicit. We elaborate further on this issue in subsection 4.3.

\subsection{Data}

In total, 371 students registered before the official deadline and showed up for the first meeting. Some students took two or three different tutorial courses at the same time and could get a discount at each occasion. The sample of 371 observations consists of 340 unique students, participating in 14 different courses and 39 different tutorial groups. Randomization of the discounts took place within each tutorial group. We want to restrict the sample to full-time students. ${ }^{13}$ Since there is no direct indicator in the data for full-time students, we drop students who are older than 26 or earn more than $€ 1200$ a month as they are more likely to be part-time students. ${ }^{14}$ We also exclude two students without exam information. The final sample contains 339 observations (312 unique students).

Table 1 provides descriptive statistics for the final sample and for each treatment group separately. The last column presents p-values of a Kruskal-Wallis equality-of-populations rank test, which tests whether at least two of the four treatment groups differ significantly from each other. Due to the $6 \%$ non-response on the post-treatment survey and some item non-response, the numbers of observations vary somewhat between variables. Observations

\footnotetext{
${ }^{13}$ For part-time students the discount is smaller relative to their income, it can be that their employer pays for the tutorial sessions or grades might matter for their employer. Therefore, one should expect a smaller sunk-cost effect for part-time students.

${ }^{14}$ When these students are included, the estimates become a bit smaller but the signs and significance levels are the same.
} 
are fairly equally divided over the treatment groups. Furthermore, the characteristics seem to be well balanced over treatment groups: only one out of 16 reported p-values is smaller than 0.10 . Around $60 \%$ of the participants are female and the average age is 21.1 years. The mean monthly income is about $€ 570$, and it is a bit higher in the groups with a lower discount. About $60 \%$ of the participants are economics students. On average, in the pretreatment survey students report that they devote 27 hours per week to studying and expect to spend slightly over 13 hours to the subject connected to the tutorial sessions. Over $30 \%$ of the students already made at least one attempt to pass the course. Students reported that they are willing to pay, on average, $12 \%$ more for the tutorial sessions than the full price and believe that participation in the sessions raises the likelihood to pass the exam by, on average, 28 percentage points. Almost half of the participants report that they received extra money from their parents to participate in the tutorial sessions. The actual number of hours that students spent on the subject, reported in the post-treatment questionnaire, is 10.8 hours per week. Finally, $45 \%$ of the students should be considered sunk-cost prone according to the hypothetical-choice questions in the questionnaire.

\section{Empirical strategy}

This section briefly describes our empirical approach. For each outcome (attendance and performance), we present results from the following five regressions:

$$
\begin{aligned}
Y_{i c} & =\alpha_{1}+\beta_{1} \text { Free }_{i}+\eta_{1} L D_{i}+\theta_{1} S D_{i}+\gamma_{1} X_{i}+\mu_{1 c}+\varepsilon_{1 i c} \\
Y_{i c} & =\alpha_{2}+\beta_{2} \text { Free }_{i}+\gamma_{2} X_{i}+\mu_{2 c}+\varepsilon_{2 i c} \\
Y_{i c} & \left.=\alpha_{3}+\beta_{3} \text { Free }_{i}+L D_{i}\right)+\gamma_{3} X_{i}+\mu_{3 c}+\varepsilon_{3 i c} \\
Y_{i c} & \left.=\alpha_{4}+\beta_{4} \text { Free }_{i}+L D_{i}+S D_{i}\right)+\gamma_{4} X_{i}+\mu_{4 c}+\varepsilon_{4 i c} \\
Y_{i c} & =\alpha_{5}+\beta_{5} \text { Discount }_{i}+\gamma_{5} X_{i}+\mu_{5 c}+\varepsilon_{5 i c}
\end{aligned}
$$

where $Y_{i c}$ is the outcome variable for student $i$ in course $c$; Free $i, L D_{i}$ and $S D_{i}$ are indicators for the different treatment groups; Discount $_{i}$ is a continuous measure for the discount; $X_{i}$ is a vector of control variables; and the $\mu_{c}$ 's are course fixed effects. The $\beta$ 's, $\eta_{1}$ and $\theta_{1}$ are the parameters of interest.

Equation (1) includes separate dummies for the three different discount levels. This tests for each discount level separately whether it has an impact compared to the "full price". 
Table 1. Descriptive statistics

\begin{tabular}{|c|c|c|c|c|c|c|c|}
\hline & \multirow[b]{2}{*}{ obs } & \multirow[b]{2}{*}{ All } & \multicolumn{4}{|c|}{ Treatment } & \multirow[b]{2}{*}{ p-value } \\
\hline & & & Free & $\mathrm{LD}$ & SD & Full price & \\
\hline \multicolumn{8}{|l|}{ Pre-treatment survey } \\
\hline Female & 339 & 0.61 & 0.62 & 0.57 & 0.64 & 0.62 & 0.87 \\
\hline Age & 338 & 21.1 & 20.8 & 21.5 & 21.0 & 21.3 & 0.23 \\
\hline Monthly income (in $€$ ) & 335 & 567 & 532 & 528 & 573 & 631 & 0.05 \\
\hline Economics or Business student & 339 & 0.60 & 0.60 & 0.65 & 0.62 & 0.55 & 0.76 \\
\hline Time spend on study (per week) & 338 & 27.0 & 26.9 & 27.5 & 27.2 & 26.4 & 0.87 \\
\hline Time spend on subject (predicted) & 337 & 13.3 & 14.5 & 12.5 & 12.7 & 13.3 & 0.79 \\
\hline First attempt for exam & 337 & 0.68 & 0.67 & 0.65 & 0.65 & 0.75 & 0.63 \\
\hline Max. willingness to pay (fraction of price) & 333 & 1.12 & 1.12 & 1.11 & 1.11 & 1.13 & 0.55 \\
\hline Predicted prob. passing without tutorial & 338 & 0.45 & 0.45 & 0.44 & 0.44 & 0.48 & 0.14 \\
\hline Predicted prob. passing with tutorial & 338 & 0.73 & 0.73 & 0.72 & 0.70 & 0.75 & 0.12 \\
\hline Course payed by parents & 339 & 0.49 & 0.51 & 0.44 & 0.54 & 0.45 & 0.63 \\
\hline \multicolumn{8}{|l|}{ Post-treatment survey } \\
\hline Sunk-costs prone & 306 & 0.45 & 0.50 & 0.44 & 0.45 & 0.42 & 0.86 \\
\hline Quality of the course (scale 1-10) & 319 & 7.19 & 7.26 & 7.45 & 7.04 & 7.04 & 0.46 \\
\hline Hours spent on subject per week & 317 & 10.8 & 11.1 & 10.9 & 10.5 & 10.8 & 0.74 \\
\hline Subjective probability of passing exam & 316 & 0.62 & 0.62 & 0.63 & 0.62 & 0.63 & 0.71 \\
\hline$\geqq 1$ of controls missing & 339 & 0.03 & 0.02 & 0.03 & 0.06 & 0.03 & 0.98 \\
\hline Total number of observations & & 339 & 86 & 79 & 87 & 87 & \\
\hline
\end{tabular}

Note: The final column present the p-value of a Kruskal-Wallis equality-of-populations rank test. 
Equation (2) only includes a dummy for the "free" treatment, and, therefore, compares paying nothing to paying something (large discount, small discount and full price jointly). This specification tests whether paying matters. ${ }^{15}$ Equation (3) includes a dummy which equals one for the "free" treatment and the "large discount" treatment, and, therefore, compares these treatments jointly to the other two treatments (small discount and full price) jointly. This specification tests whether paying (almost) nothing has a different impact than paying (almost) the full price and therefore compares two groups of participants with a large price difference between the groups and a small price difference within the groups. Equation (4) includes a dummy which is one if any discount is given and thus compares getting a discount versus paying the full price. Finally, equation (5) includes the size of the discount as fraction of the full price as the treatment variable. ${ }^{16}$

For all five equations we present results from specifications with and without control variables. The control variables are gender, age, income, maximum willingness to pay, whether the course is paid by someone else, average study time, whether it is the first attempt for the exam, and the estimated probability to pass the exam without tutorial. All control variables are measured before the randomization. Standard errors are clustered at the level of the 39 tutorial groups.

We also present results from specifications where the treatment variables are interacted with student characteristics. The first student characteristic for which we investigate interaction effects is the sunk-cost-prone indicator. This allows us to examine whether the hypothetical sunk-cost questions help to identify students who respond (stronger) to discounts. The two other student characteristics that we interact with the treatment variables are: i) an indicator for the course being paid by someone else and ii) an indicator for the student having income above the median. With these two variables we assess the relevance of income effects.

\footnotetext{
${ }^{15}$ This specific hypothesis was suggested to Ashraf et al. (2010) by NGO personnel regarding the use of Clorin. They find estimates that are large and positive, but not significant. From which they conclude that "while our data show no evidence of an effect of an act of paying, they are at least consistent with such an effect, suggesting the need for further research."

${ }^{16}$ Note that equations (2) to (5) are restricted versions of equation (1). The respective restrictions are: $(i)$ $\eta_{1}=\theta_{1}=0 ;$ (ii) $\beta_{1}=\eta_{1} ; \theta_{1}=0 ;$ (iii) $\beta_{1}=\eta_{1}=\theta_{1} ;$ (iv) $\beta_{1}, \eta_{1}$ and $\theta_{1}$ are proportionate to the discounts. Recall that the full price differs somewhat between courses. Therefore, the large and small discount are a slightly different fraction of the full price.
} 
Table 2. Effects of treatments on attendance

\begin{tabular}{|c|c|c|c|c|c|}
\hline \multirow[t]{2}{*}{$\mathrm{Eq}$} & \multirow[t]{2}{*}{ Variable } & \multicolumn{2}{|c|}{ Always present } & \multicolumn{2}{|c|}{ Fraction present } \\
\hline & & $(1)$ & $(2)$ & (3) & (4) \\
\hline \multirow[t]{3}{*}{ (1) } & Free & $-0.06(0.06)$ & $-0.11(0.07)$ & $-0.03(0.03)$ & $-0.05(0.03)$ \\
\hline & LD & $0.13(0.07)^{*}$ & $0.07(0.07)$ & $0.06(0.03)^{*}$ & $0.03(0.03)$ \\
\hline & SD & $0.03(0.07)$ & $-0.04(0.08)$ & $0.01(0.04)$ & $-0.01(0.04)$ \\
\hline (2) & Free & $-0.11(0.05)^{* *}$ & $-0.12(0.05)^{* *}$ & $-0.05(0.03)^{* *}$ & $-0.06(0.03) * *$ \\
\hline (3) & Free I LD & $0.02(0.04)$ & $-0.00(0.04)$ & $0.01(0.02)$ & $-0.01(0.02)$ \\
\hline (4) & Free $|\mathrm{LD}| \mathrm{SD}$ & $0.03(0.06)$ & $-0.03(0.06)$ & $0.01(0.03)$ & $-0.01(0.03)$ \\
\hline (5) & Discount & $0.00(0.05)$ & $-0.03(0.05)$ & $0.00(0.02)$ & $-0.02(0.03)$ \\
\hline \multicolumn{2}{|c|}{$\begin{array}{l}\text { Mean dependent variable } \\
\text { full price treatment }\end{array}$} & 0.69 & 0.69 & 0.86 & 0.86 \\
\hline \multicolumn{2}{|c|}{ Control variables } & no & yes & no & yes \\
\hline \multicolumn{2}{|c|}{ Observations } & 327 & 327 & 327 & 327 \\
\hline
\end{tabular}

Note: Regressions in the even-numbered columns include controls for gender, age, income, maximum willingness to pay, course paid by someone else, average study time, first attempt for exam and the estimated probability to pass the exam without tutorial. Standard errors in parentheses. $* * * * * *$, - estimates significantly different from zero at $1 \%, 5 \%$ and $10 \%$ level. Furthermore, course fixed effects are included and standard errors are clustered by tutorial group.

\section{Results}

We present the empirical results in three subsections. In subsection 4.1 we present estimates of the impact of the treatments on attendance and performance. Next, asses the importance of income effects and we look at heterogeneous treatment effects for sunk-cost prone students in subsection 4.2. Finally, in subsection 4.3 we characterize the sunk-cost prone students.

\subsection{Treatment effects on attendance and performance}

Table 2 presents estimation results for two measures of attendance as outcome variables: i) being always present at the tutorial sessions, and ii) the fraction of sessions attended. Columns (1) and (3) present effects without the inclusion of control variables; columns (2) and (4) include control variables.

The overall pattern for the full sample is somewhat erratic. The results from equation (1) suggest that students who received the free treatment are present less often than students who paid the full price. At the same time, students who received the large discount are 
present more often and are more likely to be always present than students who paid the full price. These findings are somewhat sensitive to the inclusion of control variables. This nonmonotone pattern is neither consistent with a sunk-cost effect nor with an income effect. The results from equation (2) show that students in the free treatment are less likely to be always present and are present less often than students from the three other treatments together. These results disappear when the students who received the large discount are added to those who received the free treatment (equation (3)). This indicates that the main difference in attendance is between the students in the free treatment and in the large discount treatment. These results do not provide evidence in support of a sunk-cost effect in the full sample on being always present or attendance rates.

Several studies find that people respond to financial incentives during the so-called hot decision stage shortly after the announcement of a payment scheme, but not anymore during the cold decision stage (cf. Gneezy and List, 2006; Leuven et al., 2011). Such a pattern is also present in the study of Arkes and Blumer (1985), who find that the sunk-cost effect is driven by behavior in the first half of the theater season. To inquire the relevance of the hot decision stage in our experiment, we look at the impact of the different treatments on students' attendance of separate session distinguished by second session, third and last (fourth or fifth). ${ }^{17}$ Because students could only participate in the experiment if they attended the first session, there is no variation in the attendance of that session. The first three columns of table 3 report the results. ${ }^{18}$ These show no support for a short-lived sunk-cost effect. Although the estimated effects of the free treatment on attending the second tutorial session are significantly negative, they are not different from the estimated effects of this treatment on attending subsequent sessions (compare the coefficients from the second equation for different sessions).

Columns (4) to (6) of table 3 report estimates of the effects of the different treatments on exam performance (passing and grade) and hours spent on the subject of related to the tutorial course (as reported by the students in the post-treatment questionnaire). Students only have an outcome for grade if they attended the exam. Results in columns (4) and (5) show that students who received the free treatment or the large discount treatment have a higher pass rate than students assigned to the other two treatments. This effect is mainly caused by the high pass rate of the students who received the large discount. This is also the group with the highest attendance rate of the exam. If we only compare treatment free to treatment large

\footnotetext{
${ }^{17}$ One course (11 students) had only three meetings. Attendance of the third meeting of that course is included in the analysis of the third meeting as well as in the analysis of the last meeting.

${ }^{18}$ Table B2 in online Appendix B reports all the results from table 3 from specifications without covariates.
} 


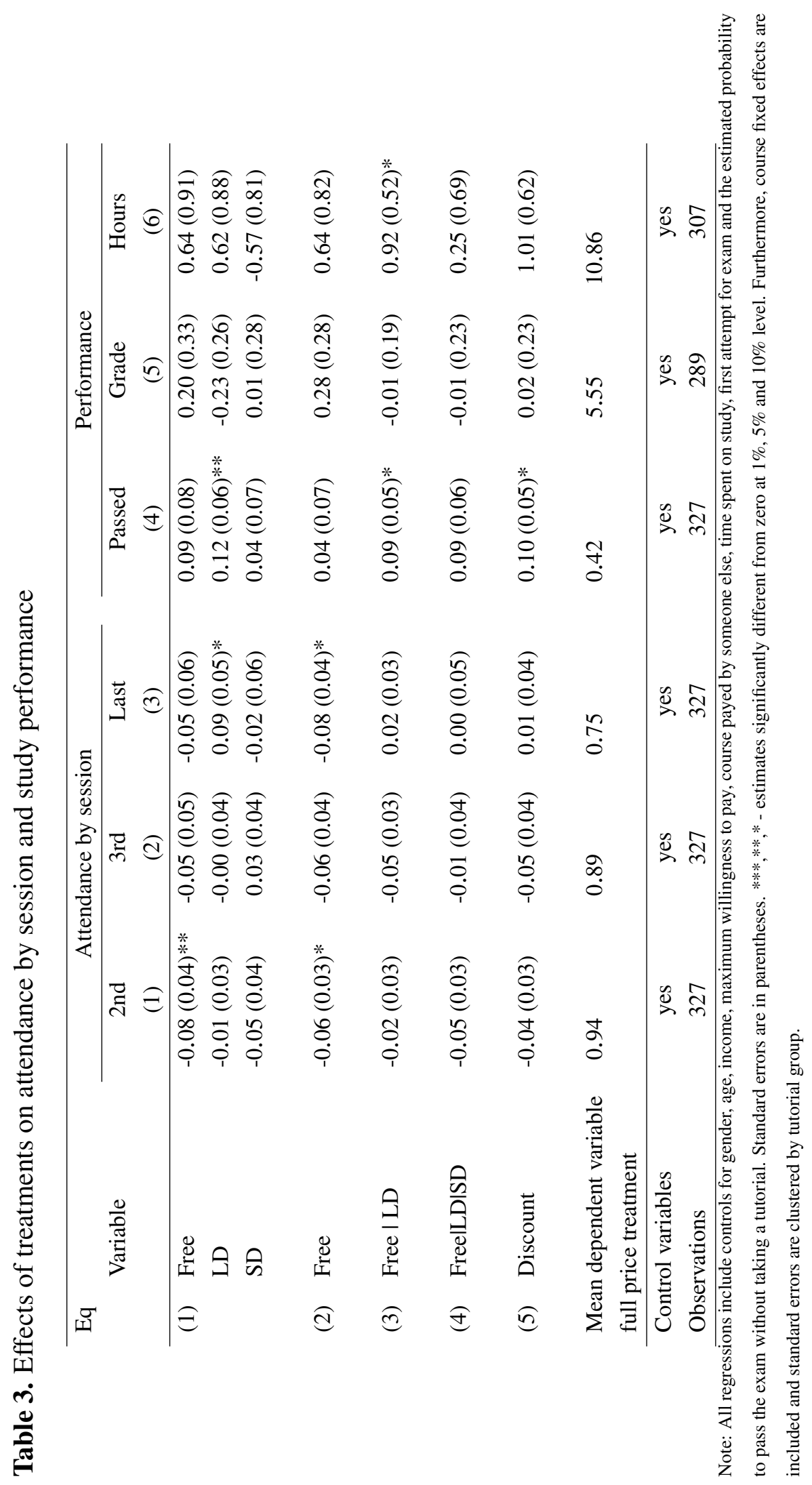


discount, there is a significant difference in attendance (always present; $p=0.02$ ), but not in pass rates $(\mathrm{p}=0.86)$. We find no significant treatment effects for the other outcome variables, grades and the number of hours spent on the subject. ${ }^{19}$

\subsection{Heterogeneity}

In this subsection we inquire whether treatment effects differ across subgroups. First, we focus on students who report that they (would have) paid the tuition fee for the tutorial course themselves. So, they did not receive extra money from their parents to pay for the course. In addition, we inquire whether effects are different for students with above and below median incomes. Next, following Ashraf et al. (2010), we single out students who are sunk-cost prone on the basis of hypothetical survey questions.

Income effects. A discount on the full price may in principle affect attendance through an income effect. Students who pay the full price for the course have less wealth and may, therefore, decide to work more, perhaps at the expense of lower attendance of the course. This mechanism works in the opposite direction of the sunk-cost effect and may thus possibly explain why we find no support for a sunk-cost effect in the full sample.

To examine this possibility we estimated treatment effects for students who are less likely to be affected by an income effect. We define such students in two ways. First, as students who did not pay for the course themselves but whose parents paid for the course. We asked students whether they paid for the tutorial course from their regular income or whether they received extra money to pay for the tutorial course from their parents. ${ }^{20}$ Second, we take students with monthly income above the median monthly income in our sample (Ashraf et al., 2010 use the same approach). The second test is probably more convincing than the first because not paying for the course yourself may mitigate the sunk-cost effect at the same time.

We re-estimated our models including interaction terms of treatment dummies with indicators for paying parents and above median income, respectively. Table 4 reports the results. If income effects hide the presence of a sunk-cost effect in the full sample, we expect to find

\footnotetext{
${ }^{19}$ The data only show a weak positive correlation between the grade and number of hours spent on the course (0.04) and fraction of tutorial sessions attended (0.06). Furthermore, fraction of tutorial sessions attended is negatively correlated to number of hours spent on the course (-0.16) which suggests some substitution of effort.

${ }^{20}$ We phrase the question like this since most students in the Netherlands receive some study allowance from their parents. We believe the relevant margin is whether students receive extra money, earmarked for the tutoring course. Paying the course from the general study allowance implies a reduction of their disposable income whereas receiving extra money for the course does not.
} 
negative treatment effects for students who did not pay themselves and for students with income above the median. We find no evidence that income effects hide a sunk-cost effect. In fact we find significantly lower attendance when assigned to the free treatment for students who paid themselves, but not for students whose parents paid, the opposite of the hypothesized income effect. This result is in line with the hypothesis that a sunk-cost effect is less likely for students whose parents paid because these students are not affected by the cost of the course, regardless of the treatment. ${ }^{21}$ Table 5 presents the results on study performance for the two subgroups. Only for the outcome variable passed there is some indication of an income effect: students who did not pay themselves and students with income above the median are somewhat more likely to pass the exam when they receive a discount. This effect is mainly driven by the students that received a large discount.

Sunk-cost prone. To examine whether the treatment effects vary with respondents' sunkcost proneness, we present results where we have interacted the treatment variables with the indicator for sunk-cost-prone students. Tables 6 to 8 show the estimates of the treatment effects of the sunk-cost-prone and the not sunk-cost-prone students. ${ }^{22}$ The effects of the discounts on the attendance of sunk-cost-prone students provide support for the hypothesis that these students attend the tutorial sessions less often and are less likely to be always present when they receive a (large) discount on the tuition fee. The results from equation (1) show that sunk-cost-prone students are 28 percentage points less likely to attend all sessions when they receive the free treatment compared to paying the full price (column 1a). The fraction of tutorial sessions that they attend is also 11 percentage points lower than that of the sunk-cost-prone students who paid the full price (column 2a). The effects on attendance of receiving the large discount or receiving the small discount are also negative for sunkcost-prone students, although these are not statistically significant. In the other equations the estimated effects of the treatment for sunk-cost-prone students in columns 1a and $2 \mathrm{a}$, are (with one exception) all significantly negative, implying that students who received a (larger)

\footnotetext{
${ }^{21} \mathrm{Next}$ to income effects, another potential contaminating factor is that students may perceive a lower price as a signal of lower quality. We believe that the procedure of letting students draw a closed envelope guarantees that students will think that the quality of the course is unrelated to the transaction price they paid. Consistent with this we find no impact of the treatment indicators on students' appreciation of the courses (results not reported). Ashraf et al. (2010) conduct a similar test when they use information from their follow-up survey about respondents' perception of product quality (p.2402).

${ }^{22}$ Because sunk-cost proneness is only known for respondents of the post-experiment questionnaire, the number of observations in this analysis is smaller than the number of observations in the previous subsection. The smallest cell contains 29 observations (sunk-cost-prone students in the full price treatment). We re-estimated the effects on attendance of table 2 for the restricted sample to make sure that the different samples are not causing our results; see Table B3 in online Appendix B.
} 


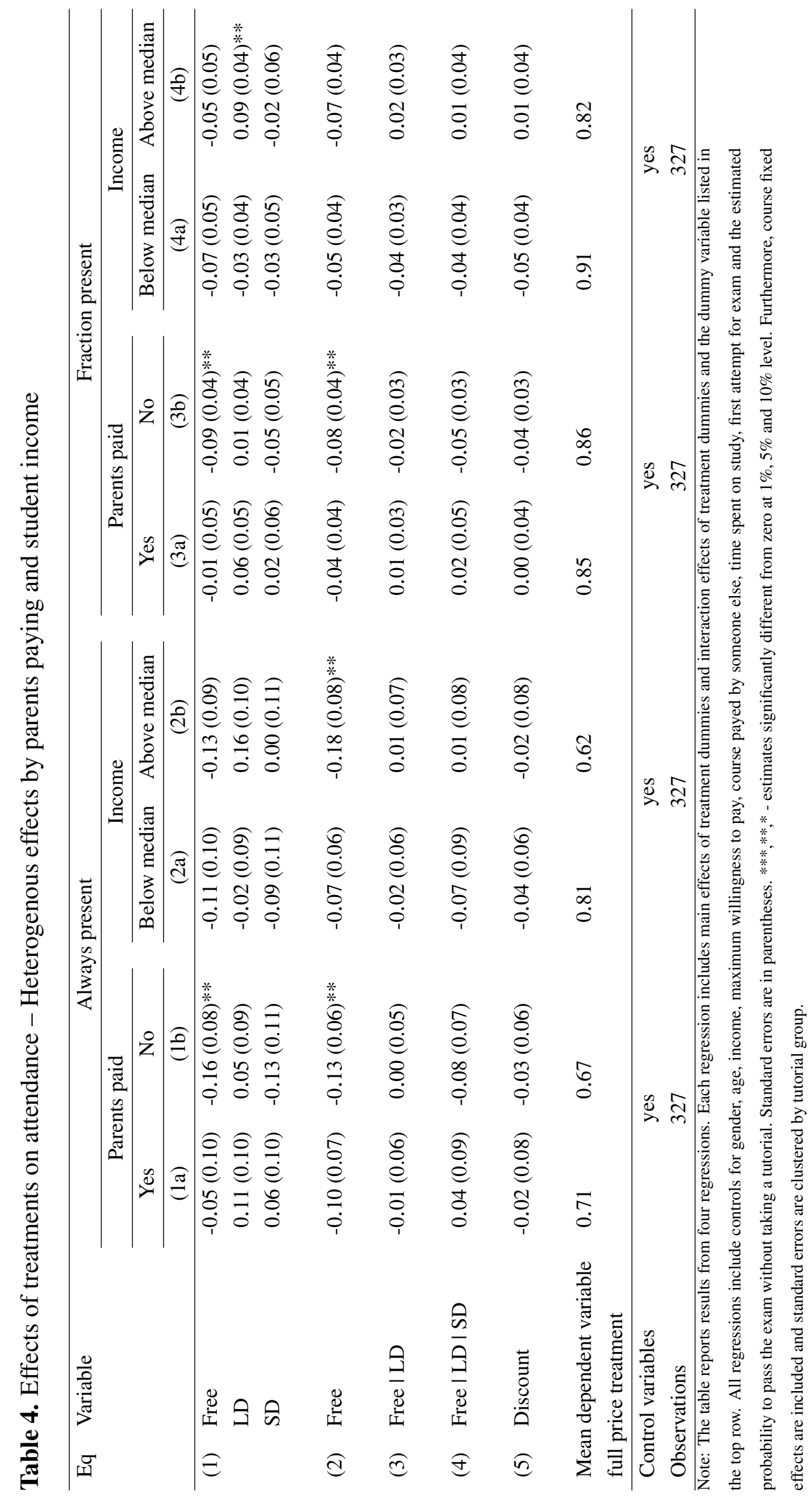




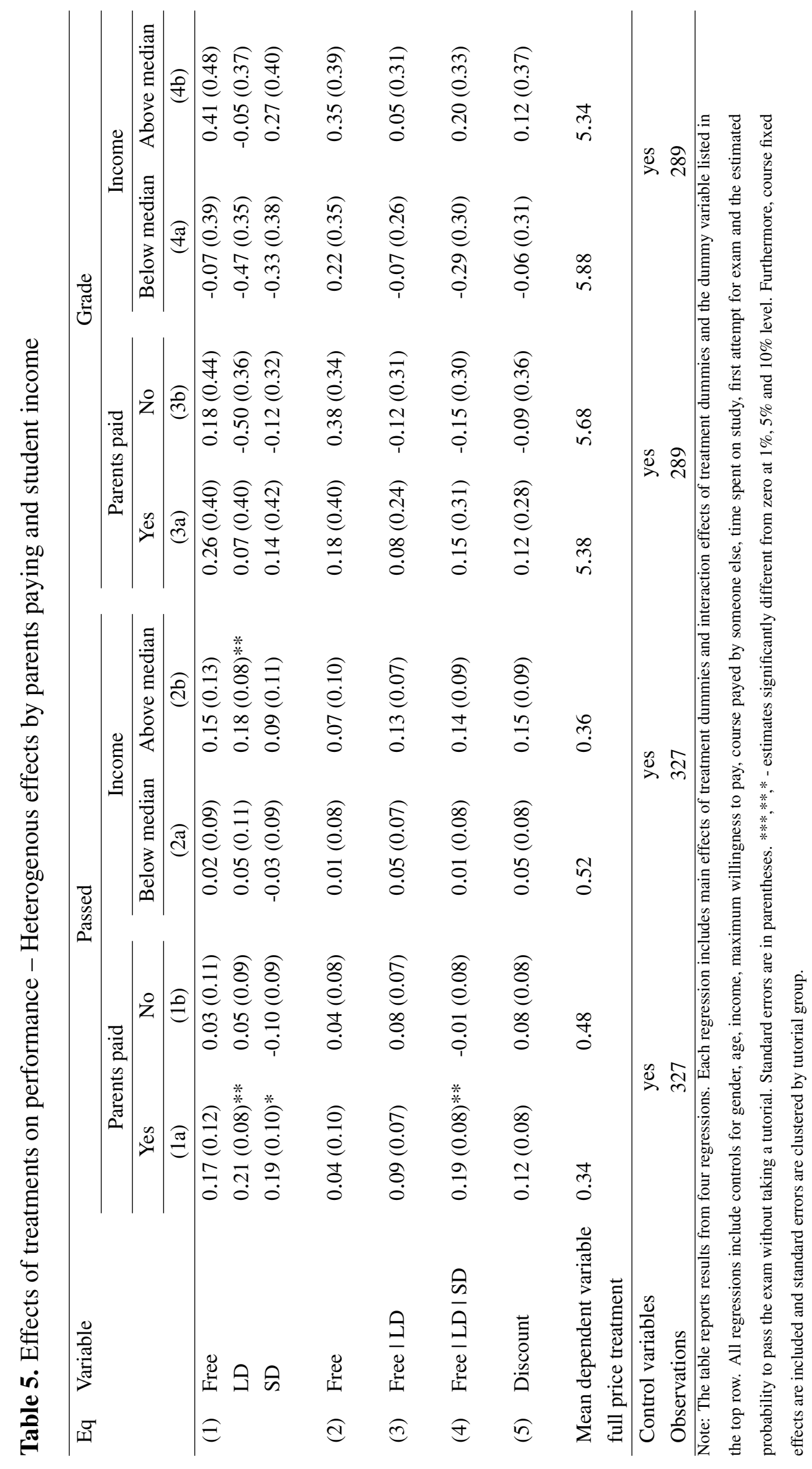


discount attended fewer tutorial sessions. ${ }^{23}$

To inquire whether the sunk-cost effect for sunk-cost-prone students is driven by the hot decision stage, table 7 looks at students' attendance in each separate tutorial meeting. For sunk-cost-prone students the effect on attendance is not yet present in the second session. It becomes negative but not significantly so for the third session, and for the last session it is negative and significant. The sunk-cost effect for sunk-cost-prone students is thus not due to the hot decision stage.

For non-sunk-cost-prone students most estimates in Tables 6 and 7 are positive. For attendance of the last meeting, some of the estimates are even statistically significant. Nonsunk-cost-prone students are more likely to attend the last meeting if they received a larger discount. This result is largely driven by students who received the large discount, they respond stronger than students who did not have to pay. While these results are somewhat puzzling, they do not affect the finding that the behavior of sunk-cost-prone students is in agreement with a sunk-cost effect.

Table 8 reports the effects on performance and hours for sunk-cost-prone students. Based on the results on attendance we might have expected that sunk-cost-prone students perform worse when receiving a larger discount. This is not what we find: their lower attendance does not translate into weaker performance. This is probably due to the fact that the impact of the discounts on attendance is not large enough. It may also be that the effect of attendance on exam performance is not so strong. Finally, there might be counteracting effects, such as a reduction in the number of hours spent on the course, that might offset any positive effects on performance. The last column of the table, therefore, reports the effect of the treatment on the number of hours that students spent on the course (self-reported). Since hours spent on the course includes the time in tutorial sessions there may be some offsetting effects.

\subsection{Characterizing sunk-cost-prone students}

From the previous analysis we can conclude that only sunk-cost-prone students appear to respond to the discounts. In this subsection we, therefore, characterize sunk-cost-prone students by regressing the indicator for being sunk-cost prone on a number of observed characteristics. Next, we discuss the caveats of identifying sunk-cost-prone students in our setting. Table 9 shows the results from these regressions. Economics and business students are less likely to be sunk-cost prone. This is also true for students who have a high willingness to pay for the

\footnotetext{
${ }^{23}$ Column 3 shows results from a regression of sunk-cost proneness on treatment variables and control variables. We return to these results in the next subsection.
} 
Table 6. Effects of treatments on attendance by sunk-cost proneness

\begin{tabular}{|c|c|c|c|c|c|c|}
\hline \multirow[t]{3}{*}{$\mathrm{Eq}$} & \multirow[t]{3}{*}{ Variable } & \multicolumn{2}{|c|}{ Always present } & \multicolumn{2}{|c|}{ Fraction present } & \multirow{2}{*}{$\begin{array}{c}\text { Sunk-cost } \\
\text { prone }\end{array}$} \\
\hline & & $\begin{array}{l}\text { Sunk-cost } \\
\text { prone }\end{array}$ & Others & $\begin{array}{l}\text { Sunk-cost } \\
\text { prone }\end{array}$ & Others & \\
\hline & & (1a) & (1b) & $(2 a)$ & (2b) & (3) \\
\hline \multirow[t]{3}{*}{ (1) } & Free & $-0.28(0.09) * * *$ & $0.05(0.11)$ & $-0.11(0.04)^{* *}$ & $0.03(0.06)$ & $0.00(0.09)$ \\
\hline & $\mathrm{LD}$ & $-0.09(0.09)$ & $0.17(0.10)$ & $-0.05(0.04)$ & $0.07(0.05)$ & $-0.02(0.08)$ \\
\hline & $\mathrm{SD}$ & $-0.15(0.11)$ & $0.04(0.12)$ & $-0.07(0.05)$ & $0.04(0.05)$ & $-0.05(0.10)$ \\
\hline (2) & Free & $-0.19(0.09)^{* *}$ & $-0.02(0.08)$ & $-0.07(0.04)^{*}$ & $-0.01(0.05)$ & $0.03(0.06)$ \\
\hline (3) & Free I LD & $-0.12(0.07)^{*}$ & $0.10(0.07)$ & $-0.04(0.03)$ & $0.03(0.04)$ & $0.02(0.06)$ \\
\hline (4) & Free | LD I SD & $-0.18(0.08)^{* *}$ & $0.09(0.09)$ & $-0.08(0.03)^{* *}$ & $0.04(0.04)$ & $-0.02(0.08)$ \\
\hline (5) & Discount & $-0.16(0.08)^{* *}$ & $0.10(0.08)$ & $-0.06(0.03)^{*}$ & $0.03(0.04)$ & $0.02(0.07)$ \\
\hline \multicolumn{2}{|c|}{$\begin{array}{l}\text { Mean dependent variable } \\
\text { full price treatment }\end{array}$} & 0.89 & 0.59 & 0.97 & 0.82 & 0.42 \\
\hline \multicolumn{2}{|c|}{ Control variables } & \multicolumn{2}{|c|}{ yes } & \multicolumn{2}{|c|}{ yes } & yes \\
\hline \multicolumn{2}{|c|}{ Observations } & \multicolumn{2}{|c|}{295} & \multicolumn{2}{|c|}{295} & 295 \\
\hline
\end{tabular}

Note: The table reports results from three regressions. The regressions in columns (1) and (2) include main effects of treatment dummies and the sunk-cost-proneness dummy, as well as their interactions. All regressions include controls for gender, age, income, maximum willingness to pay, course paid by someone else, average study time, first attempt for exam and the estimated probability to pass the exam without tutorial. Standard errors in parentheses. $* * * * * *$ - estimates significantly different from zero at $1 \%, 5 \%$ and $10 \%$ level. Furthermore, course fixed effects are included and standard errors are clustered by tutorial group. 


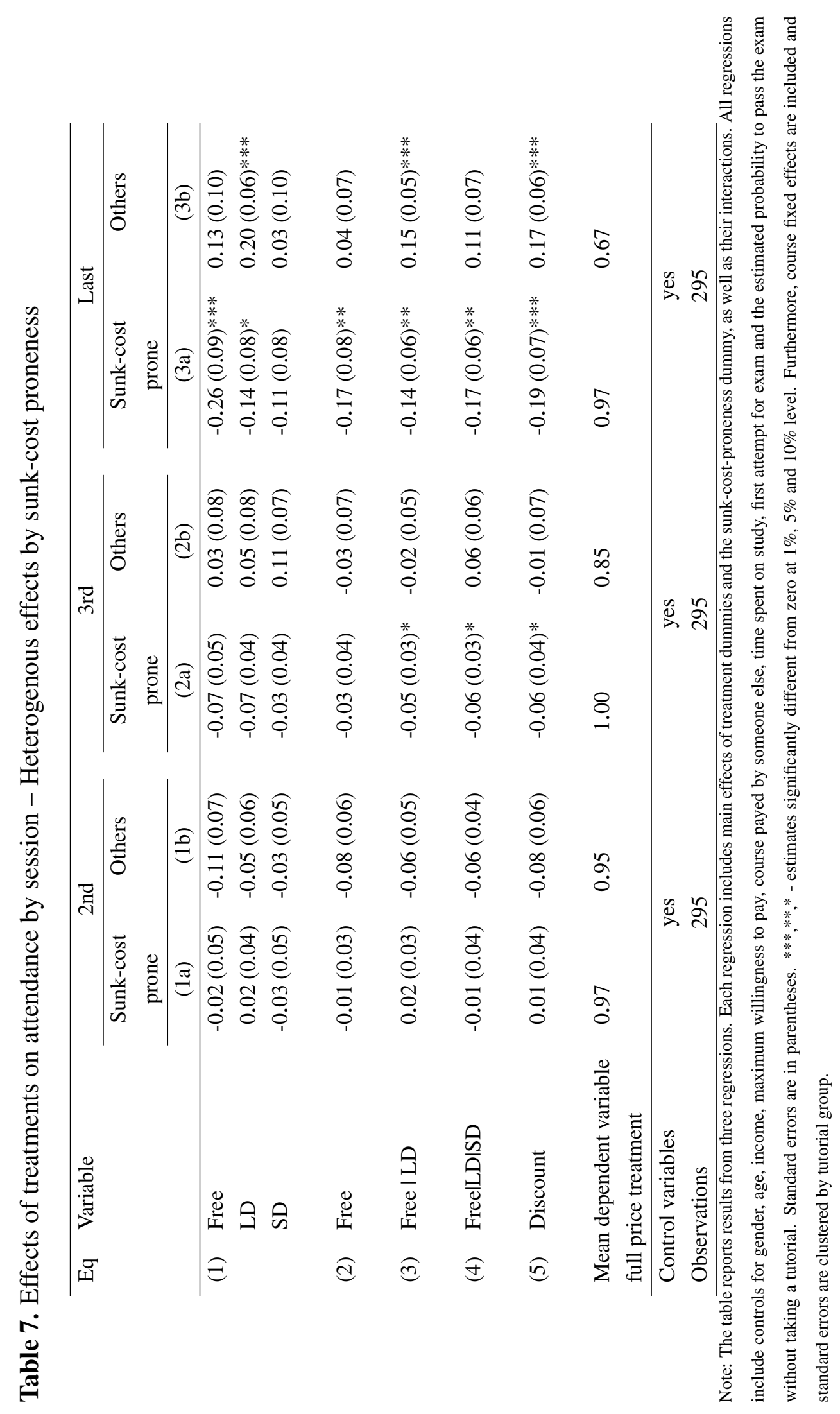




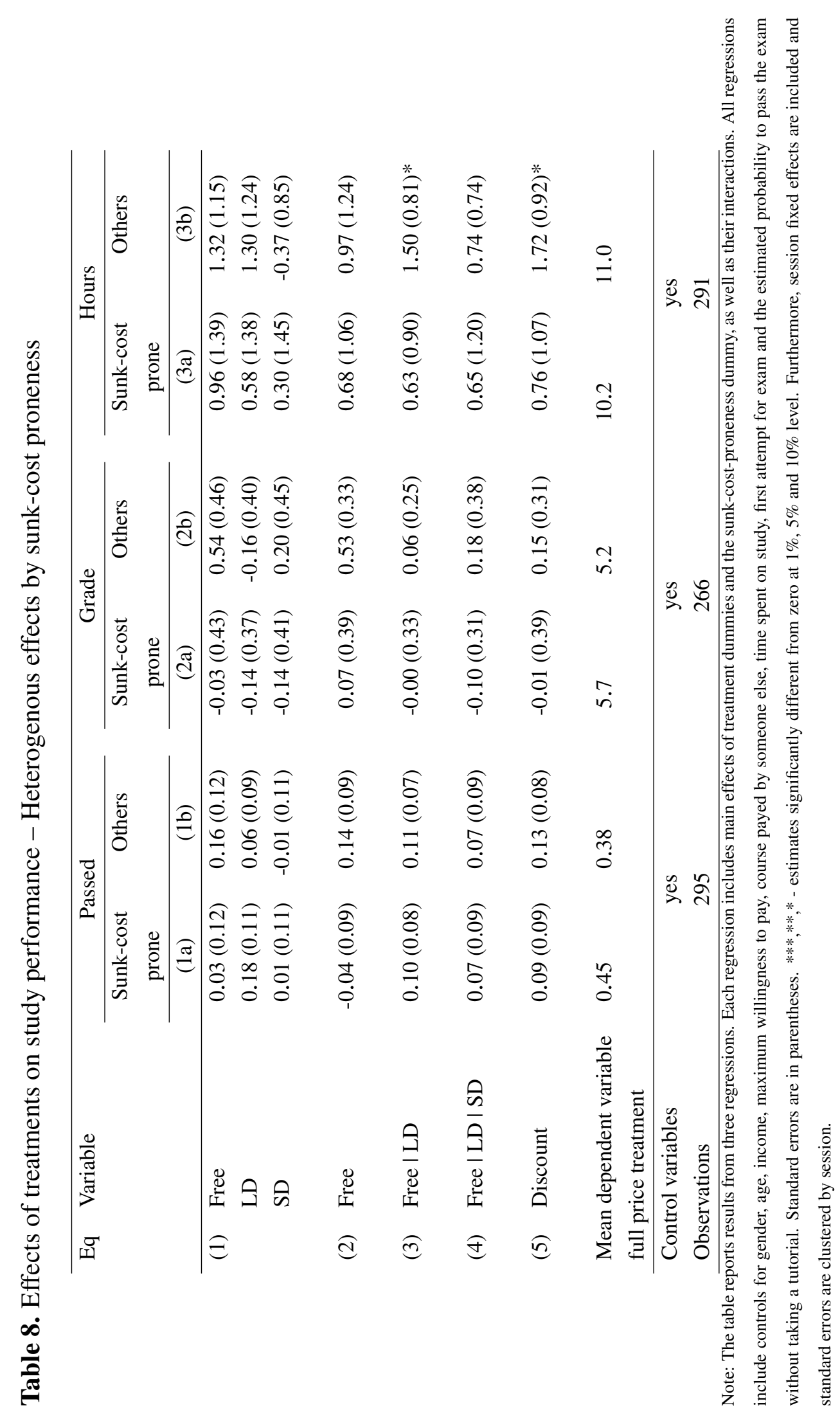


tutorial course. Otherwise the results show that the sunk-cost-prone indicator is only weakly correlated with the student characteristics that we observe.

We follow Ashraf et al. (2010) by using hypothetical survey questions to determine the sunk-cost proneness of an individual. We asked these questions in the post-treatment survey because asking them in the pre-treatment survey might make the purpose of the experiment explicit. Another reason is that Ashraf et al. also asked the hypothetical sunk-cost questions after the experiment ended. By following their example we avoid that possible differences in findings can be attributed to the moment when information was collected. A disadvantage of this procedure is that the construction of subgroups is based on a characteristic which is potentially affected by the treatments. Table 1 shows, however, that there are no significant differences in sunk-cost-proneness between the different treatment groups, although those in the free treatment are $8 \%$ points more likely to be categorized as sunk-cost prone than those in the Full price treatment. The final column in table 6 shows that the differences in sunk-cost proneness between treatment groups become (substantially) smaller, and remain statistically insignificant, when (pre-treatment) control variables are included.

Another possible worry with the sunk-cost-proneness indicator might be that students that did not attend the last class did not fill out the survey at that time. These students either sent us the questionnaire by email or we administered the questionnaire by phone. Students that answered the survey by email or phone might be more likely to give responses that identify them as sunk-cost-prone, in order to rationalize their behavior (not going to the last class). Therefore, we also include a variable that indicates whether the questionnaire was administered by email or phone. In columns 3 and 4 of table 9 we see that students that answered the questionnaire by email or phone are not more likely to be sunk-cost-prone. The coefficients are negative and not significantly different from zero. The negative sign is the reverse of what one would expect if people who answer by email or phone try to rationalize why they did not attend the last session.

Nonetheless, we can not exclude that the findings for sunk-cost-prone students are due to reverse causation in which treatment assignment and attendance jointly influence their sunkcost-prone status. This would be the case if those who did not attend the final class in the free treatment are more likely than those who did not attend the final class in the full price treatment to rationalize their behavior ex post by responding to the survey in ways that would identify them as sunk-cost-prone. ${ }^{24}$

\footnotetext{
${ }^{24}$ We thank an anonymous referee for pointing this out.
} 
Table 9. Characterizing sunk-cost-prone students

\begin{tabular}{|c|c|c|c|c|}
\hline \multirow[t]{2}{*}{ Variable } & \multicolumn{4}{|c|}{ Sunk-cost prone } \\
\hline & (1) & (2) & (3) & (4) \\
\hline Female & $0.06(0.06)$ & $-0.00(0.07)$ & & $-0.03(0.07)$ \\
\hline Age & $-0.02(0.01)^{* *}$ & $-0.02(0.01)$ & & $-0.02(0.01)$ \\
\hline Monthly income (in euros) & & $-0.00(0.00)$ & & $-0.00(0.00)$ \\
\hline Economics or Business student & & $-0.15(0.07)^{* *}$ & & $-0.21(0.07)^{* *}$ \\
\hline Time spend on study (per week) & & & & $0.00(0.00)$ \\
\hline First attempt for exam & & & & $-0.06(0.07)$ \\
\hline Max. willingness to pay (fraction of price) & & & & $-0.25(0.08)^{* *}$ \\
\hline Predicted prob. passing without tutorial & & & & $-0.17(0.17)$ \\
\hline Course paid by parents & & & & $0.01(0.06)$ \\
\hline Questionnaire by email & & & $-0.09(0.09)$ & $-0.07(0.08)$ \\
\hline Questionnaire by phone & & & $-0.16(0.13)$ & $-0.23(0.14)$ \\
\hline R-squared & 0.02 & 0.04 & 0.01 & 0.07 \\
\hline Observations & 295 & 295 & 295 & 295 \\
\hline
\end{tabular}

\section{Conclusion}

In his often-cited paper, Thaler (1980) argues that he does not believe that consumers ignore sunk costs in their every day decisions. He refers to some survey questions in Kahneman and Tversky (1979), to examples in which governments fail to ignore sunk costs, and to introspection to convince the reader. Yet, he acknowledges that gathering evidence to test the sunk-cost hypothesis is complicated due to selection bias. The recent studies by Ashraf et al. (2010) and Cohen and Dupas (2010) report about field experiments which have been designed to take selection issues into account. Both studies fail to find significant sunk-cost effects.

Our field experiment is comparable to those of Ashraf et al. (2010) and Cohen and Dupas (2010), but we believe two features of our design give the sunk-cost hypothesis a better chance than their designs. First, we offer substantially larger discounts than the previous authors, which should increase the chance of finding a sunk-cost effect (cf. Garland and Newport, 1991; Rodrik, 2009). Second, the previous studies look at products where the opportunity costs of actually using them appear much smaller than in the case of attending sessions of an extra-curricular course. The opportunity costs of actual usage seems an essential element of the sunk-cost examples provided by Thaler.

Despite our efforts to stack the deck in favor of finding sunk-cost effects, we find no 
evidence of such effects for our full sample. Discounts on tuition fees have, on average, no impact on class attendance in our sample of students who signed up for extra-curricular courses. We inquired whether the absence of sunk-cost effects can be attributed to income effects, but find no evidence of that. Finally, we followed Ashraf et al. (2010) who used hypothetical survey questions to single out individuals with a proneness to take sunk costs into account. For this subsample we find a significant sunk-cost effect on attendance: sunkcost prone students who receive a larger discount are less likely to attend. This does, however, not translate into better performance for these students. We acknowledge, however, that the measurement of sunk-cost proneness has some caveats.

While we believe that the size of the discounts and the context of our experiment gave the sunk-cost hypothesis a better chance than previous studies, it may of course be the case that we did not go far enough. It may be that with larger discounts and/or higher opportunity costs of actual usage, a larger share of the sample does not ignore sunk costs.

\section{References}

Arkes, H. R. and Blumer, C. (1985). The psychology of sunk cost. Organizational Behavior and Human Decision Processes, 35(1):124-140.

Ashraf, N., Berry, J., and Shapiro, J. M. (2010). Can higher prices stimulate product use? Evidence from a field experiment in Zambia. American Economic Review, 100(5):23832413.

Bryan, G., Karlan, D., and Nelson, S. (2010). Commitment devices. Annual Review of Economics, 2:671-698.

Cohen, J. and Dupas, P. (2010). Free distribution or cost-sharing? Evidence from a randomized malaria prevention experiment. Quarterly Journal of Economics, 125(1):1-45.

Dynarski, S. M. (2003). Does aid matter? Measuring the effect of student aid on college attendance and completion. American Economic Review, 93(1):279-288.

Eyster, E. (2002). Rationalizing the past: A taste for consistency. Unpublished working paper.

Frederick, S., Loewenstein, G., and O'donoghue, T. (2002). Time discounting and time preference: A critical review. Journal of economic literature, 40(2):351-401. 
Friedman, D., Pommerenke, K., Lukose, R., Milam, G., and Huberman, B. (2007). Searching for the sunk cost fallacy. Experimental Economics, 10(1):79-104.

Garland, H. and Newport, S. (1991). Effects of absolute and relative sunk costs on the decision to persist with a course of action. Organizational Behavior and Human Decision Processes, 48(1):55-69.

Gneezy, U. and List, J. A. (2006). Putting behavioral economics to work: Testing for gift exchange in labor markets using field experiments. Econometrica, 74(5):1365-1384.

Hidalgo, D., Onofa, M., Oosterbeek, H., and Ponce, J. (2013). Can provision of free school uniforms harm attendance? Evidence from Ecuador. Journal of Development Economics, 103(1):43-51.

Kahneman, D. and Tversky, A. (1979). Prospect theory: An analysis of decision under risk. Econometrica, 47(2):263-292.

Kane, T. J. (2003). A quasi-experimental estimate of the impact of financial aid on collegegoing. Working Paper 9703, National Bureau of Economic Research.

Koch, A., Nafziger, J., and Skyt Nielsen, H. (2014). Behavioral economics of education. Journal of Economic Behavior \& Organization, Forthcoming.

Leuven, E., Oosterbeek, H., Sonnemans, J., and Van der Klaauw, B. (2011). Incentives versus sorting in tournaments: Evidence from a field experiment. Journal of Labor Economics, 29(3):637-658.

Levitt, S., List, J., Neckermann, S., and Sadoff, S. (2012). The behavioralist goes to school: Leveraging behavioral economics to improve educational performance. NBER Working Paper 18165.

Meyer, D. J. (1993). First price auctions with entry: An experimental investigation. Quarterly Review of Economics and Finance, 33(2):107-122.

Offerman, T. and Potters, J. (2006). Does auctioning of entry licences induce collusion? An experimental study. Review of Economic Studies, 73(3):769-791.

Phillips, O. R., Battalio, R. C., and Kogut, C. A. (1991). Sunk and opportunity costs in valuation and bidding. Southern Economic Journal, 58(1):112-128. 
Rodrik, D. (2009). The new development economics: We shall experiment, but how shall we learn? In Cohen, J. and Easterly, W., editors, What Works in Development? Thinking Big and Thinking Small. Brookings Institution Press, Washington, DC.

Thaler, R. (1980). Toward a positive theory of consumer choice. Journal of Economic Behavior \& Organization, 1(1):39 - 60 .

Van der Klaauw, W. (2002). Estimating the effect of financial aid offers on college enrollment: A regression-discontinuity approach. International Economic Review, 43(4):12491287. 


\section{A Courses}

Table A1. Courses offered at universities

\begin{tabular}{llccc}
\hline & Study program & Full price (in $€$ ) & \# groups & \# students \\
\hline VU University Amsterdam (VU) & & & & \\
Business Mathematics & Economics and Business & 75 & 3 & 34 \\
Financial Accounting and Bookkeeping & Economics and Business & 75 & 2 & 17 \\
Quantitative Business Analysis & Economics and Business & 75 & 1 & 10 \\
Statistics I (premaster) & Economics and Business & 75 & 2 & 21 \\
Statistics II (premaster) & Economics and Business & 75 & 5 & 57 \\
Mathematics (premaster) & Economics and Business & 75 & 3 & 35 \\
Statistics II & Psychology & 60 & 2 & 16 \\
Meten en Diagnostiek II & Psychology & 60 & 2 & 13 \\
Utrecht University (UU) & & & & \\
Methodology and Statistics I & Social Sciences & 65 & 4 & 34 \\
Methodology and Statistics (premaster) & Social Sciences & 65 & 1 & 10 \\
University of Amsterdam (UvA) & & & & \\
Econometrics & Economics and Business & 75 & 2 & 18 \\
Mathematics and Statistics I & Economics and Business & 75 & 4 & 35 \\
University of Groningen (RUG) & & & & \\
Statistics I A (Dutch) & Psychology & 65 & 3 & 27 \\
Statistics I A (English) & Psychology & 65 & 3 & 23 \\
Statistics II part II & Psychology & 65 & 2 & 21 \\
\hline
\end{tabular}




\section{B Additional tables}

Table B1. Effects of treatments on response and method of response

\begin{tabular}{|c|c|c|c|c|}
\hline $\mathrm{Eq}$ & Variable & $\begin{array}{l}\text { Survey } \\
\text { response } \\
\text { (1) }\end{array}$ & $\begin{array}{l}\text { Questionnaire } \\
\text { by email } \\
\text { (2) }\end{array}$ & $\begin{array}{c}\text { Questionnaire } \\
\text { by phone } \\
\text { (3) }\end{array}$ \\
\hline \multirow[t]{3}{*}{ (1) } & Free & $0.01(0.04)$ & $0.06(0.04)$ & $-0.03(0.06)$ \\
\hline & LD & $0.08(0.03)^{* *}$ & $-0.03(0.02)$ & $-0.02(0.05)$ \\
\hline & $\mathrm{SD}$ & $0.04(0.04)$ & $0.02(0.03)$ & $-0.01(0.06)$ \\
\hline (2) & Free & $-0.03(0.03)$ & $0.07(0.03)^{*}$ & $-0.02(0.05)$ \\
\hline (3) & Free I LD & $0.02(0.02)$ & $0.01(0.02)$ & $-0.02(0.03)$ \\
\hline (4) & Free | LD | SD & $0.04(0.03)$ & $0.02(0.03)$ & $-0.02(0.05)$ \\
\hline (5) & Discount & $0.02(0.03)$ & $0.02(0.02)$ & $-0.03(0.04)$ \\
\hline \multicolumn{2}{|c|}{$\begin{array}{l}\text { Mean dependent variable } \\
\text { full price treatment }\end{array}$} & 0.90 & 0.04 & 0.16 \\
\hline \multicolumn{2}{|c|}{ Control variables } & yes & yes & yes \\
\hline \multicolumn{2}{|c|}{ Observations } & 327 & 295 & 295 \\
\hline
\end{tabular}

Note: All regressions include controls for gender, age, income, maximum willingness to pay, course paid by someone else, average study time, first attempt for exam and the estimated probability to pass the exam without tutorial. Standard errors in parentheses. ***,**** estimates significantly different from zero at $1 \%, 5 \%$ and $10 \%$ level. Furthermore, course fixed effects are included and standard errors are clustered by tutorial group. 


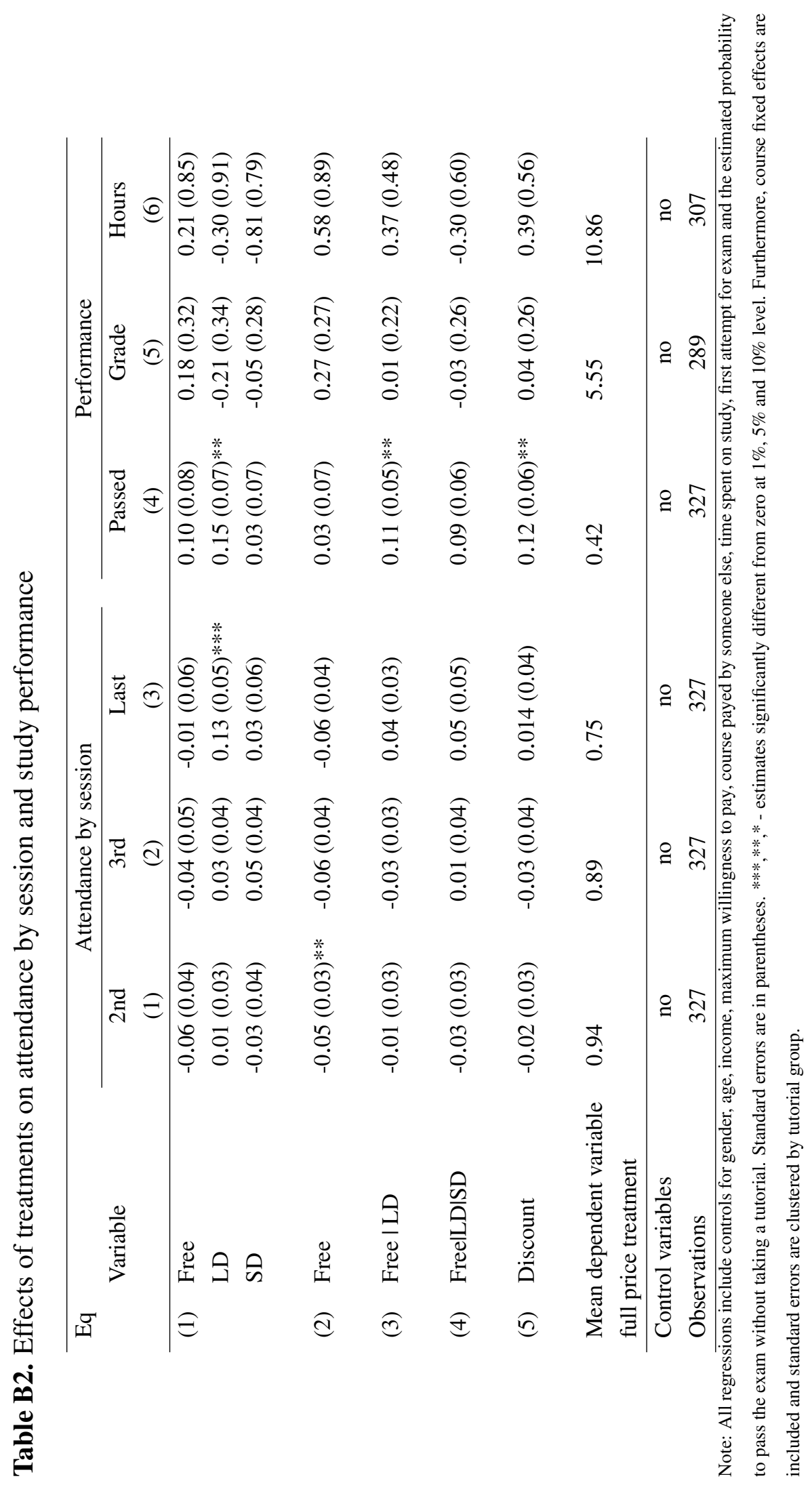




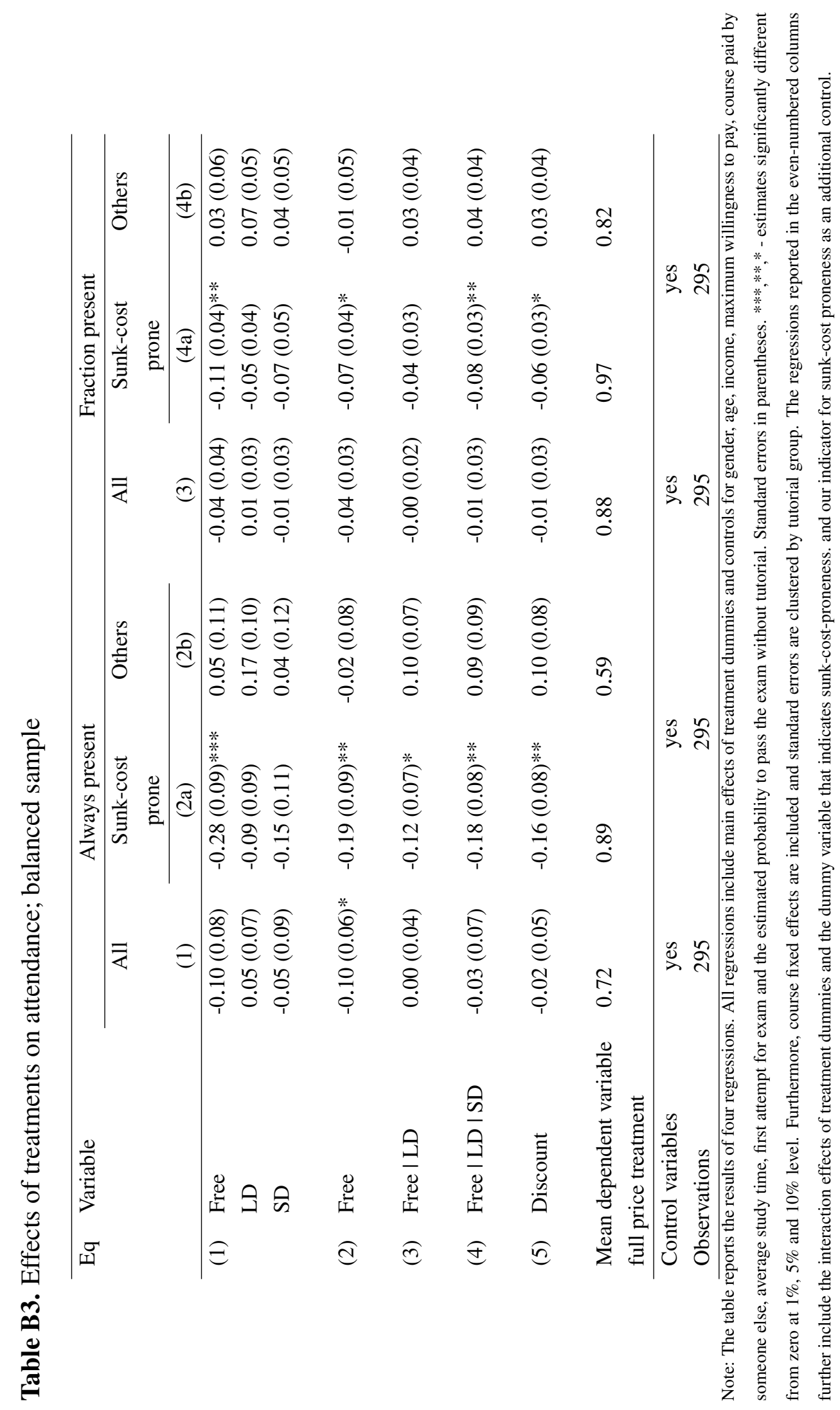




\section{The questionnaires}

The questionnaires in this appendix assume a price of $€ 65$ and 5 sessions. This was adjusted depending on the tutorial sessions in question.

\section{Pre-treatment questionnaire}

Dear student,

We ask you to take part in a study carried out by the VU and the UvA. In this study you have a $1 / 4$ chance to receive the following discounts on the fee of the tutoring course: $€ 0$, $€ 10, € 55$ or $€ 65$ discount. By completely filling out the questionnaire below you participate in the study. Your information will only be used, anonymized, for our research on study behavior. After filling out the questionnaire, or choosing not to, the fee has to be paid and the potential discount will be determined. If you have any questions regarding the study you can ask them at that time.

\section{Personal information}

1. Name: 2. Student number:

3. Phone number: 06-.......

4. Email address: .............

5. Gender: $\square$ Male $\square$ Female

6. Age: ...... years

\section{Education}

7. Since when do you study?

Since $20 \ldots$

8. Home many hours a week do you spend on your studies, on average?

...... hours per week

9. How many hours do you expect to spend on this course, including the hours spend in tutoring courses? 
...... hours per week

10. Why did you choose to follow tutoring courses for this subject?

11. Did you take tutorial courses through [name of the study association] before? If so, for which subject?

Yes for the subject ............ $\square$ No

12. Did you take the exam for this subject before? If so, how often?

$\square$ Yes, ............ time(s) before $\square$ No

13. How many of the 5 classes do you intend to follow?

1 class $\square 2$ classes $\square 3$ classes $\square 4$ classes $\square 5$ classes

14. How large do you estimate the probability that you will pass the exam?

Without taking this tutoring course: .......\%

After following this tutoring course: ....... \%

\section{Background}

15. With which type of math did you graduate high school?

Math A $\square$ Math B $\square$ Math C $\square$ Math D $\square$ Other, i.e. .....

16. With what math grade did you graduate high school (In case of a non-Dutch exam, please translate the grade to a comparable Dutch grade)?

17. Did you receive extra money from your parents to pay for this course or did you pay for it out of your regular income?

From regular income $\square$ Extra contribution of parents $\square$ Other, i.e. ....... 
18. What is your average monthly income (including student aid and contributions from your parents.)?

$€ \ldots \ldots$

19. What is the maximum amount you would be willing to pay for these tutoring courses?

$€ \ldots \ldots$

20. Do you have friends in this tutorial group? If so, what are their names?

Yes

Names friends:

$\square$ No 


\section{Post-treatment questionnaire}

Name:

Student number:

Teacher:

Course

Day: Time:

In addition to the usual evaluation questions some questions were added for the study of the UvA and the VU in which most of you participated. The answers to this questionnaire will be treated confidentially and anonymous and will only be used for this study.

\section{General:}

The probability I would recommend this tutoring class to a friend is:

(lowest) 12345678910 (highest)

\section{Booklet:}

The quality of the booklet was:

(lowest) 12345678910 (highest)

The booklet covers all subjects in the course:

(lowest) 12345678910 (highest)

All important subjects in the course were covered with enough assignments:

(lowest) 12345678910 (highest)

\section{Teacher:}

The teacher was knowledgeable about all important subjects

(lowest) 12345678910 (highest)

The teacher motivated me to try my best

(lowest) 12345678910 (highest)

The teacher was good

(lowest) 12345678910 (highest) 


\section{Other participants:}

Other participants were involved and worked hard during the tutoring classes:

(lowest) 12345678910 (highest)

Other participants were well prepared for the tutoring classes:

(lowest) 12345678910 (highest)

\section{Final evaluation}

In general I assess these tutoring courses with:

(lowest) 12345678910 (highest)

Would you participate in another tutoring course organized by [Name of the study association] in the future? If not, why?

Yes $\square$ No, because ...............

\section{Attendance}

How many and which of the tutoring classes did you miss?

Class 1: $\square$ Present $\square$ Partly absent $\square$ Absent

Class 2: $\square$ Present $\square$ Partly absent $\square$ Absent

Class 3: $\square$ Present $\square$ Partly absent $\square$ Absent

Class 4: $\square$ Present $\square$ Partly absent $\square$ Absent

Class 5: $\square$ Present $\square$ Partly absent $\square$ Absent

If you missed 1 or more classes, what were the reasons for your absence (multiple answers possible)

$\square$ I was ill $\square$ Something else intervened $\square$ I didn't think the class would be useful Other, which is ........ 


\section{Course}

How many hours did you spent on this course, including the hours spent in tutoring courses ...... hours per week

How large do you estimate the probability that you will pass the exam?

............\%

\section{Discount}

Participants in this tutoring course were able to get a discount. The size of the discount was randomly determined. How large was the discount you received?

$€ \ldots \ldots$

In case you got a discount, what did you do with the money?

I gave it back to my parents

I added it to my regular income

I spent it on something special, which is $\ldots \ldots \ldots \ldots .$.

$\square$ Other, which is $\ldots \ldots \ldots \ldots \ldots \ldots$

$\square$ I didn't get a discount

What did you think of the fact that people could get a discount?

\section{Background}

Indicate for each of the following statements the extent to which you agree with it.

On the whole, I am satisfied with myself.

(completely disagree) 1234567 (completely agree) 
I certainly feel useless at times.

(completely disagree) 1234567 (completely agree)

I prefer to something that challenges my thinking skills over something that doesn't require me to think.

(completely disagree) 1234567 (completely agree)

I trust my initial hunches.

(completely disagree) 1234567 (completely agree)

Suppose you bought a bottle of juice for $€ 2$,-. When you start to drink it, you realize you don't really like the taste.

Would you finish drinking it? $\square$ Yes $\square$ No

Now suppose you bought exactly the same bottle of juice for $€ 5$,-. When you start to drink it, you realize you don't really like the taste.

Would you finish drinking it? $\square$ Yes $\square$ No

Now suppose you bought exactly the same bottle of juice for $€ 1,-$. When you start to drink it, you realize you don't really like the taste.

Would you finish drinking it? $\square$ Yes $\square$ No

General remarks about the tutoring course 